\title{
Developing a Smart Helmet Based on the Internet of Things to Manage Hearing Problems in the Construction Projects
}

\author{
'Hamidreza Abbasianjahromi', Vahid Pourali Shadhy² and \\ Amirhassan Beykian'
}

First submission: 10 July 2020; Accepted: 22 November 2020; Published: 8 December 2021

To cite this article: Hamidreza Abbasianjahromi, Vahid Pourali Shadhy and Amirhassan Beykian (2021). Developing a smart helmet based on the Internet of things to manage hearing problems in the construction projects. Journal of Construction in Developing Countries, 26(2): 231-250. https://doi.org/10.21315/jcdc2021.26.2.11.

To link to this article: https://doi.org/10.21315/jcdc2021.26.2.11

\begin{abstract}
Construction sites are renowned as the noisiest places that may cause hearing loss to workers. Lack of awareness about the level of harmful sounds causes more prevalence of hearing loss than other industries. This article intends to solve this issue by an innovative idea that is designing a wearable device called "smart helmet" (SH). The SH uses the concept of the Internet of things (IOT) for real-time monitoring workers' hearing health in construction sites. $\mathrm{SH}$ works online to send notifications in the presence of harmful sounds and offline due to storing data to analyse workers' health conditions. The results are divided into two sections: The first section presents the detail of the architecture, hardware and software of the SH and the second section offers a formula to convert noisy situations into allowable working time. By combining the proposed procedure and SH's prepared data, the allowable working time can be calculated for workers. The results of applying this device in practical projects show that steelworkers are more at risk than the others with exposure to $98 \mathrm{~dB}$ sounds.
\end{abstract}

Keywords: Noise-induced hearing loss, Internet of things, Wearable device, Construction project

\section{INTRODUCTION}

Every year, several construction workers have hearing loss due to exposure to a high noise level at the workplace (Lee, Kim and Hong, 2019). Hearing loss decreases the quality of life and increases other occupational diseases (Kantová, 2017). In the United States (US), OSHA (Occupational Safety and Health Administration) has a 90-dB permissible sound level for an eight-hour work. However, according to NIOSH (National Institute for Occupational Safety and Health), noise-induced hearing loss (NIHL) is usually caused by prolonged exposure to $85 \mathrm{~dB}$ or higher (NIOSH, 2003). NIOSH recommends a contact level of $85 \mathrm{~dB}$ for eight hours. The collected data from research in the US show that $18 \%$ of workers had hearing loss problems in this country and construction workers place in the third position concerning the frequency of this problem (Masterson et al., 2013). According to the research conducted by Fernández et al. (2009), construction workers face noise pollution from $60 \%$ to $70 \%$ of the day. Leensen, van Duivenbooden and Dreschler (2011) measured the sound level for some most common jobs in the construction industry and they showed that the rate of sound level goes beyond $85 \mathrm{~dB}$. Building Trades National Medical Screening Program data show that $58 \%$

\footnotetext{
'Department of Civil Engineering, KN Toosi University of Technology, Tehran, IRAN ${ }^{2}$ Islamic Azad University, South Tehran Branch, Tehran, IRAN

*Corresponding author: habasian@kntu.ac.ir
} 
of workers have hearing issues caused by noises in their workplace (Dement et al., 2018). The amount of hearing loss depends on the position. Approximately $71.4 \%$ of the welders have hearing issues compared to $54 \%$ of the electricians (Dement et al., 2018). The received data show that:

1. NIHL is one of the common occupational diseases in every country's construction industry in which workers' hearing health has not been considered appropriately.

2. Two criteria, including the level of sound and the noise exposure duration, determine the severity of the hearing loss.

3. Workers in the construction industry should be aware of the level of generated sounds in their working area and constraint themselves to the standard duration of the sound's exposure in order to protect themselves from hearing problems.

Due to the fact that NIHL is one of the most challenging dilemmas among workers in the construction industry and the costs of health care providers can increase dramatically (Szymański, 2017), the considerations of the safety team should be focused on to solve this issue. There are two approaches to deal with NIHL:

1. Reducing the level of sounds generated by different devices in construction projects. This strategy needs to apply some state-of-theart devices or new technologies. For example, old machines should be repaired or replaced by new ones. Since this approach is along with the famous statement "Prevention is better than cure", it has a high priority in preventing NIHL (Suter, 2002). On the other hand, it requires considerable financial sources that reduce the applicability of this approach.

2. Protecting the ears from harmful noises. While the first strategy cannot be applied beneficially, putting on personal protective equipment (PPE) and decreasing the duration of exposure are appropriate strategies for this dilemma. Sakhare and Chakravarty (2020) believed that the continuous monitoring of sounds in the workplace and warning to workers when exposed to high-level sounds, is the best way of protecting workers.

The prerequisite for protecting a worker from destructive situations is that the person should be aware of the disastrous conditions. In many cases, the workforce does not pay proper attention to the Health, Safety and Environment (HSE) team's protection instructions or the allowable time to exposure to harmful sounds. Moreover, thanks to human resources' limitations in the HSE team, the team cannot monitor whole workers simultaneously to inform or alarm them. While the HSE team is responsible for alarming and controlling workers in projects concerning HSE considerations, the number of workers and construction sites' extensiveness are two significant barriers for real-time and simultaneous controlling. 
Nowadays, the pace of technological progress is dramatically high. One of the new technologies is the Internet of Things (loT), which is a necessary tool toward moving to Industry 4.0 (Li, 2018). Moreover, its impact on different industries is substantial (Dave et al., 2018). loT refers to the network of physical objects that interact with each other over the Internet by aiding other hardware such as sensors and software to facilitate management issues such as monitoring and controlling. Through this network, communications between these objects occur without the need for human intervention and it occurs at any moment and place. IoT has been applied in various situations in the construction industry (such as lean prefabricated construction [XU et al., 2018], integrating with building information modelling [Dave et al., 2018], smart building [Park and Rhee, 2018], safety [Kim, Ryu and Kang, 2018], etc.) and now its application is expanding. Without utilising IOT, simultaneous management and monitor of several objects are challenging. Since the construction projects have usually been distributed in a large area, there is a need to enhance the remote collaborations between different parties (Louis and Dunston, 2018). By implementing loT, other objects (including workforce, machines, materials, etc.) can be connected, managed and monitored appropriately and remotely.

To satisfy one of the important prerequisites of the second strategy which is to enhance the level of the worker's awareness about the noise pollution, this article intends to develop a new device to alarm workers in facing adverse conditions. Consequently, the appearance of new developments such as IoT, presents a beneficial opportunity to meet this goal. This article applies a mechanism based on loT to increase personal hygiene protection in noise pollution in construction sites without worries about real-time and simultaneous controlling. This wearable device that authors called the "smart helmet" (SH) can monitor each worker concerning the level of sound by using an intelligent loT-based system at any moment. The SH can notice workers when they are in risky situations about disastrous high decibel sounds. Moreover, the HSE group receives an alert to track and remove this issue. The system can eliminate the actual presence of HSE people at the site and boost their virtual presence and accuracy. Subsequently, by implementing the offline section of the $\mathrm{SH}$, the HSE team can analyse workers' environments regarding the intensity of sounds and the allowable duration time for each worker. The device can bring a control system for occupational health. According to Marchiori et al.'s (2017) study, the control system can improve occupational health. The rest of the article is organised as follows: In the next section, a thorough review of the literature will be done. In the third section, the applied methodology, the steps of developing the $\mathrm{SH}$ and its hardware and software are described in detail. The SH was applied in practical projects and results are presented in the next section and finally, the conclusion section is offered.

\section{LITERATURE REVIEW}

Since this article's topic combines two subjects, including NIHL in the construction industry and IOT application, this section is divided into two categories to review the previous research in more detail. 


\section{NIHL in the Construction Industry}

Hong (2005) developed an investigation to study the frequency and characteristics of hearing loss among engineers in the American construction industry. His results showed that hearing problems have been showed in more than $60 \%$ of engineers. House, Sauvé and Jiang (2010) investigated the effect of age and the severity of hand-arm vibration syndrome with hearing loss. Their findings revealed both criteria have a direct impact on hearing loss. Leensen, van Duivenbooden and Dreschler (2011) measured the hearing threshold levels among Dutch construction workers. Their results showed that the duration of exposure and hearing loss has a direct relation similar to ISO 1999. The study was conducted by Seixas et al. (2011) to investigate the impact of utilising wellconstructed hearing personal devices by training and providing some additional supports such as noise level indicators. They found a positive correlation between the studied variables. Abbasianjahromi and Talebian (2018) developed research among Iranian workers in the construction industry. They found that one of the common non-articulated diseases among building workers in hearing loss. Lee, Kim and Hong (2019) examined the adverse impact of different stages and machines concerning noise pollution. They found that the demolition stage is the most annoying step in the construction projects and some equipment such as a breaker, pile driver and hammer compactor are ranked as the noisiest ones. Ning et al. (2019) focused on reducing noise pollution by optimising the site layout about the place of equipment generated noise pollution. Couth et al. (2019) compared the level of hearing loss and tinnitus in high-risk industries such as the construction industry to low-risk industries. They concluded that the level of hearing loss in the agricultural industry is higher than in other sectors, but the tinnitus problem is common in construction workers. De la Hoz-Torres et al. (2020) spoke about the sound map as a useful tool for identifying places with high-level sounds. They believed that preparing a sound map can be a strategic tool for protecting workers from hearing loss.

\section{Application of IoT in the Construction Industry}

There are several exciting areas in the construction industry for implementing IOT. Zhou and Ding (2017) developed a safety barrier system based on the IOT platform for working underground projects. In their study, IoT was utilised as an early warning system when the hazard energy was detected. Kanan, Elhassan and Bensalem (2018) proposed a wearable device based on an loT platform, which focuses on two features: (1) Power-saving and (2) Real-time sensing systems to protect workers from danger zones. Developing a cloud based loT platform for managing prefabricated construction projects is the subject of $\mathrm{XU}$ et al. (2018). They applied three tools, including radio frequency, directional antennas, ultrasound waves, in their platform. Louis and Dunston (2018) developed an loT-based system for real-time decision making in construction projects. They prepared a framework using a practical and sensor-agnostic system based on the loT networks to collect data from a situation, process data, decide an appropriate decision and feedback to the objects connected by the loT platform. Tang et al. (2019) believed that the integration of IOT and building information modelling (BIM) can improve construction projects' efficiency. They reviewed some research to reveal challenges and future opportunities for the integration of 
BIM and IOT. Ding et al. (2018) applied a BIM-IOT framework to monitor and control the steel bridge in real-time. They opined that their work is along with the context of Industry 4.0. Niu, Anumba and Liu (2019) developed a framework to improve the synergy between IOT, cyber-physical systems and smart construction objects. They believed that the proposed framework could help manage complex and dynamic construction projects when real-time communication and rapid decision are needed.

The literature survey shows that first, hearing loss in the construction industry is essential than in other industries. But most of them focused on variables that correlated with the severity of hearing loss and some researchers concentrated on solving the problem of hearing loss. The main deficiency in this area is the lack of applying new technologies such as loT for problem-solving. The second section showed that the frequency of utilising loT in the construction industry, specifically in health and safety issues, is becoming popular.

\section{METHODOLOGY}

Since this article intends to solve the low awareness of construction workers about noise pollution and NIHL by applying an loT-based wearable device, the present study is applied research. To reach this goal, related works in the realms of the application of IOT in the construction industry and noise pollution were studied. Moreover, in terms of technology, what facilities are required for this research. After that, by utilising hardware and software in the context of the IOT, a new wearable device called the $\mathrm{SH}$ was generated to improve the level of awareness of people engaging in construction projects. To develop the $\mathrm{SH}$, the level of disastrous sound based on some standards is determined and the sensors from the surrounding area obtain the initial information. Then, data are processed with the use of other tools. If the limit exceeds, with the help of embedded systems and based on the loT platform, an alert will send to the worker and the safety group regarding the person in the high-risk environment. After identifying the appropriate hardware for this research, the software aspect was considered and the programming required for the research was done. After making the $\mathrm{SH}$, calibration experiments were carried out on the helmet to better match the reality. The collection of data and information was continuous, regular and online through loT-based technologies used in this device. Finally, the $\mathrm{SH}$ was utilised in some practical cases to test its applicability and bring some impressive results about the impact of noise pollution on construction projects. In the case study, those at the most significant risk of NIHL (less than $5 \mathrm{~m}$ distance to noise pollution) are fully investigated.

The steps for developing the SH are as follows:

1. Developing the conceptual system architecture

IOT systems' conceptual architecture is changing over time, but the conventional architecture consists of three layers: perception, network and application (Ngu et al., 2016; Silva, Khan and Han, 2018). This article used a conventional architecture system. In the perception layer, sensors are placed and data collection is done in this layer. In the network layer, 
transmitting data to the application layer is done in a safe condition. Finally, the application layer helps in analysing and processing data according to the users' intends. Figure 1 depicts the conceptual system architecture. In the first layer, sensors are responsible for detecting sounds. The outputs of sensors should be processed by the central processing unit (CPU) to be able to readable by other devices. In the second layer, data generated by the CPU is transmitted to the application layer. In the SH, two options including, offline and online, have been predicted. When the alarm should be sent to the worker and the HSE team, the online status is active, but the offline status will be active for storing data for analysis. Finally, in the application layer, data is analysed and the desired outputs are extracted.

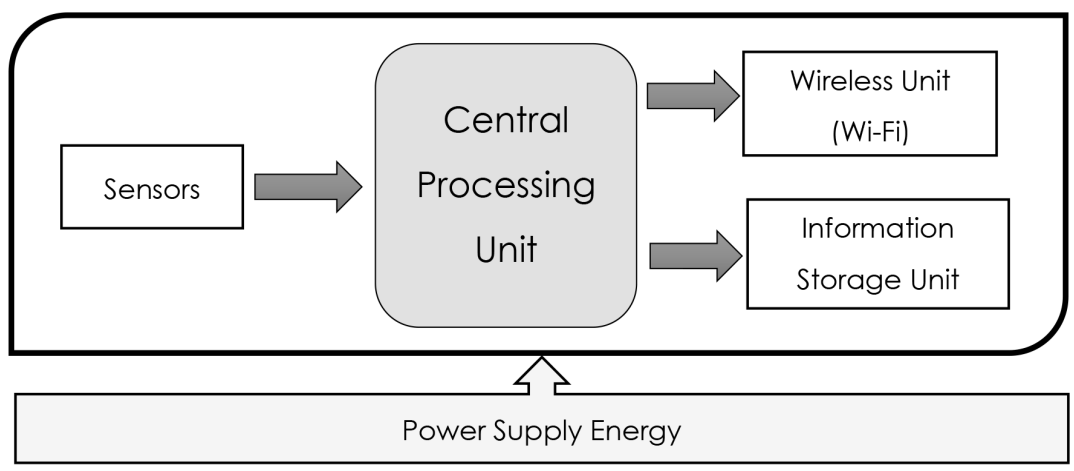

Figure 1. Different units used in the project and their relationships

2. Hardware selection

According to the developed architecture, two categories of hardware should be selected. The first one is related to the perception layer and the second one is related to the network layer. The chosen hardware for these layers are as follows:

(a) Perception layer hardware

(i) Sensor

The KY-037 audio sensor is a high sensitivity sound module that has both digital and analog outputs. The digital signal sensitivity of this sensor is adjustable by a potentiometer. If the ambient sound level rises, the digital output will be sent and when the volume level is exceeded, a light will turn on in this module. The microphone continuously senses the intensity of the surround sound through the microphone. In addition to the digital measurement capability, the sensor can process ambient noise in analog (continuous) waves, convert the voltage to the processor range. Figure 2 depicts the KY-037 sensor. 

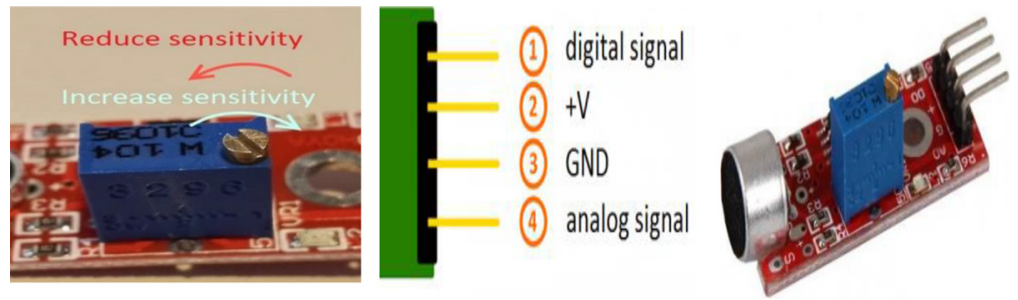

Figure 2. The KY-037 sensor

Sound sensors provide inaudible output according to their mechanism. The reason is that these sensors deliver their outputs in the form of differential voltages. In other words, these sensors measure the intensity of the ambient noise. Still, they do not provide the output $\mathrm{dB}$ format, which is intended for this research. They only deliver non-conceptual voltages in different situations. To solve this challenge, a specific formula (as shown in Equation 1) should be used to convert the sensors' output voltage to the $\mathrm{dB}$ of the research according to the type of input device (sound intensity sensor). In this way, the random numbers of the output voltage in each period enter this formula and the output number of this formula means the $\mathrm{dB}$ of the environment that the user understands.

$$
L=20 \log \frac{V_{\text {out }}}{V_{\text {in }}}
$$

Where $L$ is the level of sound in $d B$ and $V_{\text {out }}$ and $V_{\text {in }}$ is the input and output voltage. In the KY-037 sensor, there is an instrument like a bolt, as depicted in Figure 2, that a user can twist it to increase or decrease the sensitivity of the sensor. In other words, when the sensor's sensitivity increases, it means that in the higher level of sounds, the sensor will be generated an output voltage. In this way, the system will be able to record the sounds higher than permissible rates.

The effect of dust on sensors' performance is a challenging problem that should be taken into account by the user. Due to the nature of the construction industry, the presence of dust is inevitable. Fine aggregates and dust can damage the sensor and bringing some errors in detecting the sound. As a consequence, it is suggested that the HSE team should control and calibrate the device regularly. 
(ii) $\mathrm{CPU}$

The CPU in this study is one of the most essential components. Considering that various parts have been used to achieve the research's purpose (sensors, storage devices, etc.), a comprehensive and robust processor that can control these components and receive the necessary outputs is needed. It is necessary to save for later processing. CPU applied in this study should have two important features: (1) Low weight and (2) Low energy consumption. Because the designed system should be portable by the individual without disturbing, weight is an important criterion in choosing the processor boards. In addition to weight, because the system should be used in different environments (portability), it must be equipped with a wireless power source (battery). These energy sources have capacity constraints; therefore, the selected CPU should have a minimum energy consumption.

Arduino is an open-source electronic microcontroller designed to make it easier to interact with objects or environments. The hardware encompasses an open-source hardware board designed around the AVR Atmel Microcontroller. Figure 3 depicts the Arduino board. Because Arduino's software and hardware are open sources, it can be easily created using the software, schematics and printed circuit boards (PCB). For programming in the Arduino environment, it does not have to do with low-level codes regarding the microcontroller's configuration. Still, by using the high-level $\mathrm{C}++$ language to write the programme and using a USB cable on the board, it will upload an appropriate code on the board. The concepts of objectivity are also fully supported in the Arduino environment. Multiple libraries for different Arduino boards and popular pieces written by other people have added to Arduino's workability. Many manufacturers of electronic components have also produced modules for use in Arduino boards.

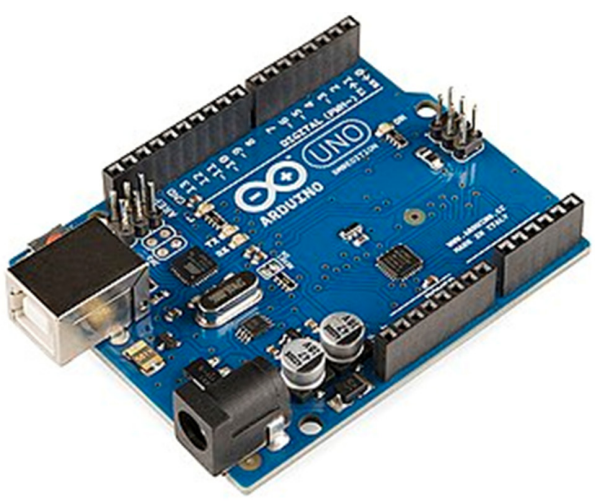

Figure 3. Arduino board Uno model 
(iii) Network layer hardware

(a) Wireless unit

One of the most challenging components in loT systems is the wireless unit. This module is used for receiving and sending data from a device to the data centre. Features, bandwidth, cost, security and energy consumption are some parameters that should be taken into account when selecting the best wireless unit. In this article, owing to the limitation of supplying appropriate energy, the Wi-Fi board was selected to transfer data on the site. It should be noticed the energy consumption of this module is considerable, so that the device can be alternatively worked online and offline. The Wi-Fi module used in the SH is ESP8266 and is depicted in Figure 4.

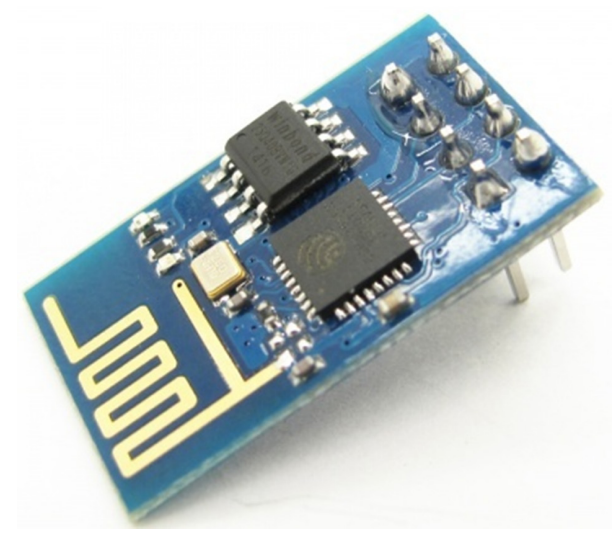

Figure 4. ESP8266- Wi-Fi module

(b) Information storage unit

To create a data storage unit in this research, several criteria for choosing the type of memory have been considered. Three important criteria for choosing storage should be considered are weight, dimensions and capacity.

For some reasons, including the low weight of this type of memory, much smaller dimensions, lower power consumption, higher data transfer speeds, etc., the SD memory card was accepted for this research. Another challenge is selecting a compatible memory reader for the board after choosing an appropriate storage unit. Figure 5 depicts the form of this module. 


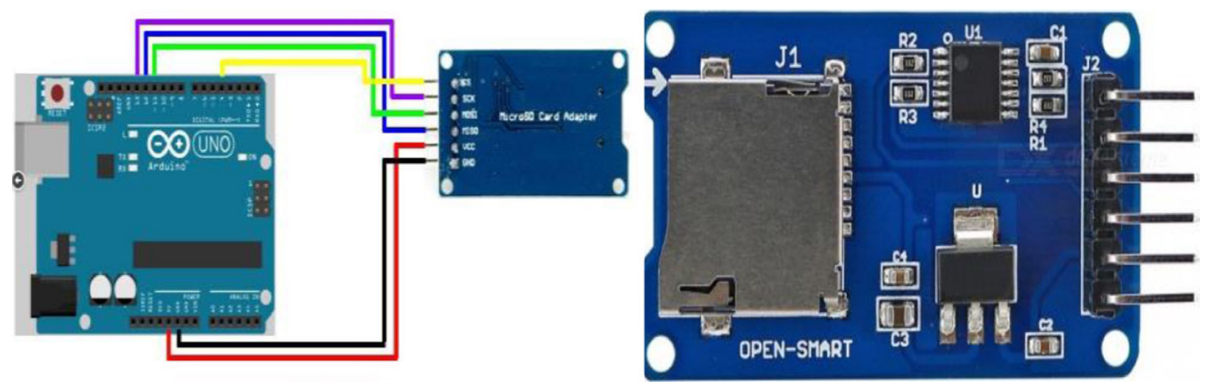

Figure 5. SD card memory module and how to connect it to Arduino

(c) Power supply unit

Some critical criteria for selecting the type of energy source are needed to do this research, including capacity, weight, dimensions and cost. In this research, it was decided to choose a rechargeable $9 \vee$ battery, taking into account the system's total consumption during the activity period (energy consumption of the processor, sensors, storage devices, etc.) and the operating voltage required by Arduino.

(iv) Application layer

The main objective of the application layer is to process and analyse some data to extract some results. In this research, the goal is to design a system that receives, processes and outputs the status of sounds around workers. To do this, the sensor information is used as the initial input data; furthermore, this information is examined by the processor-specific criteria with programming criteria. The following processed data is transferred online for giving the notification or stored on the SD memory card for further analysis. These two sections described as follows:

(a) Online application layer

To check the permissible rate of sounds around workers in real-time, the SH should send a notification to the HSE team and give some alarms to workers and any person responsible for the site. To do this, the Wi-Fi module can send a notification to the centre when the rate of noise exceeds a permissible rate. While informing the HSE team is necessary, workers' awareness of the harmful sounds or the allowable time is not obeyed is more important than the HSE team. The worker can get away from the place or use different PPE to reduce the level of sounds. Some lights are installed in the helmet to depict and alarm workers. When the red light is on, it shows that the level of sounds or the allowable duration is not obeyed. Figure 6 illustrates these lights. 


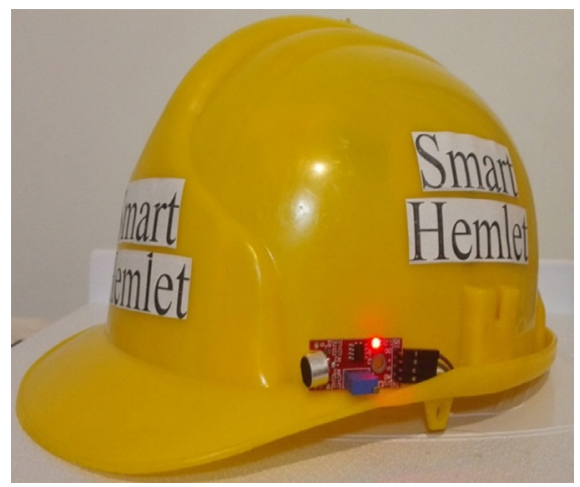

Figure 6. The light for alarming to workers

(b) Offline application layer

Data should be stored on the SD card and analysed during projects to monitor workers' health conditions in terms of encountering sounds. To meet this goal, the output of Equation 1, which is based on $\mathrm{dB}$ per command execution period, is a specific number at a particular time that these numbers should be stored in an environment for the subsequent processing that the user intends to do. For this purpose, to programme the SD memory card, the processed data storage environment is introduced and each period of the programme repeat, a number on the SD memory card will be registered. At the end of the process, there is a need to set a time for each programme repetition period to process and record the input information again. In this study, this time processing is considered half a second, which can be changed; if the repetition period is less, the energy consumption would be greater. The output is presented as a table that is readable by Microsoft Excel software. These numbers are presented in the table, which has different recorded values every half a second. This table indicates how long a worker has been in an infected environment with excessive sound levels. The mean of the recorded numbers can be used to extract the average pollution of the environment.

\section{DATA ANALYSIS}

To analyse the hearing health conditions of workers, the stored data should be analysed appropriately. This article presents a new approach to transform the obtained results by the $\mathrm{SH}$ to applied information. Suppose that if the SH designed for a person during a work period (one day) has $n_{r}$ data registrations, that is, $n_{r}$ cases of high-frequency noise above the permissible rate (for example, $85 \mathrm{~dB}$ ) and 
recorded by the sensor. The duration of each case (according to the programming) was 0.5 seconds in this device (while it is possible to change this timespan). Using Equation 2, it can be calculated how much time the person encounters the harmful sounds.

$$
T_{h}=n_{r} \times T S
$$

Where $T_{h}$ is the amount of time that person faces the harmful sounds, $n_{r}$ is the number of records by the SH and TS is the timespan has been set by the wearable device. For example, for a person with 1,000 records and timespan $0.5 \mathrm{sec}$, the total time that a person faces to harmful sounds is $500 \mathrm{sec}$ during his work period.

The next step is to calculate every worker's actual working time concerning exposure to harmful sounds. According to NIOSH (2003), the permissible noise level is $85 \mathrm{~dB}$ in eight hours' exposure time per $24 \mathrm{~h}$. When the environmental noise pollution rises from $85 \mathrm{~dB}$ to $88 \mathrm{~dB}$, the allowed working time during a work period is only $4 \mathrm{~h}$ (half the previous model) (OSHA, 1998). Similarly, the permitted working hours will be halved for every $3 \mathrm{~dB}$. When a worker works in an environment with $88 \mathrm{~dB}$ of pollution for 20 min, this means the worker is in normal condition ( $85 \mathrm{~dB}$ ) for 40 min (working time doubles). In this example, the permissible sound intensity is matched by the ratio of mathematics. Equation 3 converted the duration of the exposure to the harmful noises into a normal mode. Using Equation 3, the HSE team can find every worker's real working time in a project.

$$
T_{r}=T_{h} \times 2\left(\frac{N E_{\text {ave }}-P N}{3}\right)
$$

Where $T_{r}$ is the real working time in the normal mode, $P N$ is the permissible level of sounds near the ear for working $8 \mathrm{~h}$ per $24 \mathrm{~h}$ working time, $N E_{\text {ave }}$ is the average of the intensity of sounds that the worker encounters during his work (as explained in previous section, the sensor converts the received sounds to the voltage if it exceeds the permissible sounds and then the voltage can be transferred to sound measurement by using Equation 1 in the Microsoft Excel datasheet). In the mentioned example, if the $N E_{\text {ave }}$ is 94 , the $P N$ is $85 \mathrm{~dB}$ and $T_{h}$ is $500 \mathrm{sec}$, the real working time of the worker concerning the harmful sounds is $4,000 \mathrm{sec}$.

This person has worked for $500 \mathrm{sec}$, but because of an environment with noise pollution higher than the limit and without any means of protecting the ear, his working hours should be considered 4,000 sec.

Using the results of this section, the HSE team would be able to develop an allowed timetable for every worker after the working day. The allowable working timetable can show how much each person is allowed to work in harmful or normal situations for the rest of the day or month to prevent NIHL. It should be noticed that the difference between normal and harmful conditions can be diagnosed by the level of sounds recorded by the SH. For example, suppose the permissible level of sound is $85 \mathrm{~dB}$. In the environment with sounds higher than this threshold is categorised in harmful situations and, vice versa; the situation with lower sound is the normal condition. 


\section{Research Practical Test}

The research has been tested in the construction environment to determine the device's strengths and weaknesses and see if this system correctly targets the research or faces new challenges in practice. Several building projects in Tehran, the capital of Iran, were selected randomly and the application of the $\mathrm{SH}$ was studied. Three types of workers, including stonecutters, steelworkers and carpenters, have been tested. In each category, five persons in 15 building projects have been selected. The participation of workers was voluntary. They wore the designed SH for approximately a month to investigate the helmet's usage and analyse their harmful duration time.

The workers who used SH were questioned to investigate the SH's weight and convenience compared to other helmets. Although changing and charging the battery (the battery are able to provide the needed power for about $56 \mathrm{~h}$ in each charging cycle) and access to the SD card bring some limitations. Still, they are not very important that reduce efficiency and productivity during their works. One of the limitations that they declared was the lack of ability to see the alarming light. To remove it, the authors added the sound of the bell to the board for alarming workers. Figure 7 depicts some examples of the SH usages in different building projects.

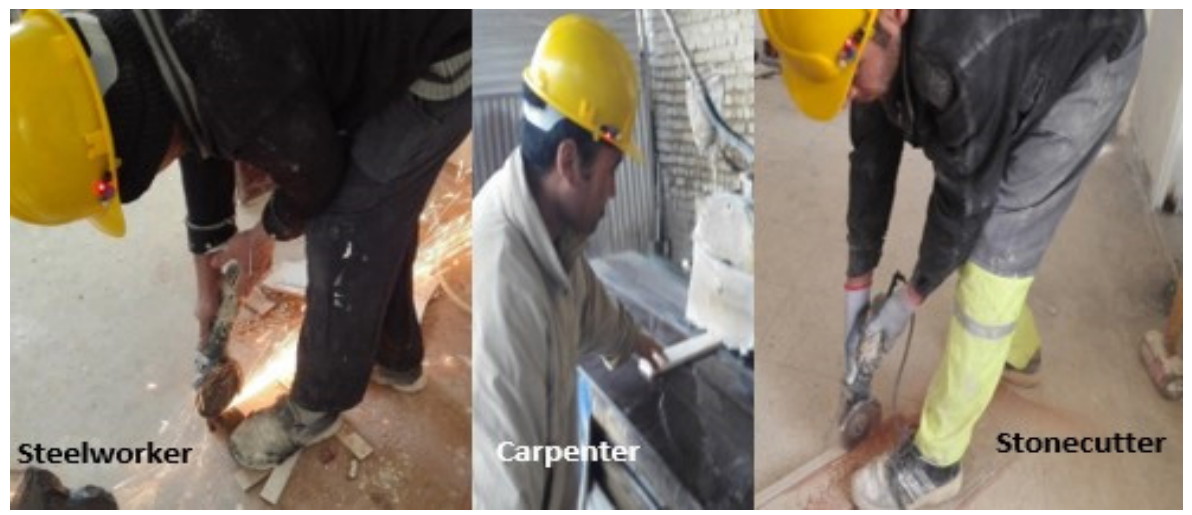

Figure 7. Some examples of the SH usage in different building projects

The second result of the case study is to analyse the harmful duration of studied groups. The data obtained from each group were analysed and described as follows:

1. Stonecutters: The first group of workers who tested this SH was stonecutters that have been cut in two conditions dry and wet conditions. Results showed that the average noise in this type of work is $96 \mathrm{~dB}$ in dry conditions. When workers worked in wet conditions, the average noise decreased to $90 \mathrm{~dB}$. It means using the water can reduce noise levels and consequently increase the duration of safe work. The results of the real working time for three days are presented in Table 1. 
2. Steelworkers: The second group of workers who tested this SH was steelworkers. Results showed that the average noise that existed in this type of work is about $98 \mathrm{~dB}$. Among the three considered groups, steelworkers place in the first rank according to exposure to harmful sounds. The results of the real working time for three days are presented in Table 1.

3. Carpenters: The third group of workers who tested this SH is carpenters. Results showed that the average noise that existed in this type of work is about $89 \mathrm{~dB}$. Their results were very similar to the stone cutters in the wet conditions.

The recorded data for real working time in three days are presented in Table 1. In the last row, the average intensity of sounds that each construction worker has encountered is presented. For example, on the first day of the experiment, the stonecutter has encountered to average noise of about 95.5 $\mathrm{dB}$. Moreover, the number of records depict that how many times workers encounter harmful situations. For example, on the second day of the experiment, the steelworker encounter 2,827 times harmful situations in terms of hearing loss.

Table 1. The sample of recorded data of $\mathrm{SH}$ in three days of the experiment

\begin{tabular}{|c|c|c|c|c|c|c|c|c|c|}
\hline \multirow{2}{*}{ Intensity (dB) } & \multicolumn{3}{|c|}{$\begin{array}{c}\text { Stonecutter } \\
\text { Conditions (Numbers) }\end{array}$} & \multicolumn{3}{|c|}{$\begin{array}{c}\text { Carpenter Condition } \\
\text { (Numbers) }\end{array}$} & \multicolumn{3}{|c|}{$\begin{array}{l}\text { Steelworkers } \\
\text { (Numbers) }\end{array}$} \\
\hline & $\begin{array}{l}\text { 1st } \\
\text { Day }\end{array}$ & $\begin{array}{l}\text { 2nd } \\
\text { Day }\end{array}$ & $\begin{array}{l}\text { 3rd } \\
\text { Day }\end{array}$ & $\begin{array}{l}\text { 1st } \\
\text { Day }\end{array}$ & $\begin{array}{l}\text { 2nd } \\
\text { Day }\end{array}$ & $\begin{array}{l}\text { 3rd } \\
\text { Day }\end{array}$ & $\begin{array}{l}\text { 1st } \\
\text { Day }\end{array}$ & $\begin{array}{l}\text { 2nd } \\
\text { Day }\end{array}$ & $\begin{array}{l}\text { 3rd } \\
\text { Day }\end{array}$ \\
\hline 85 & 236 & 113 & 191 & 38 & 254 & 215 & 81 & 113 & 71 \\
\hline 86 & 225 & 106 & 206 & 48 & 276 & 190 & 88 & 123 & 42 \\
\hline 87 & 221 & 123 & 187 & 51 & 268 & 190 & 104 & 105 & 40 \\
\hline 88 & 244 & 140 & 206 & 50 & 232 & 178 & 111 & 136 & 59 \\
\hline 89 & 215 & 136 & 183 & 45 & 259 & 203 & 83 & 118 & 52 \\
\hline 90 & 212 & 145 & 195 & 56 & 246 & 181 & 97 & 114 & 50 \\
\hline 91 & 215 & 132 & 180 & 44 & 265 & 172 & 95 & 124 & 63 \\
\hline 92 & 201 & 117 & 209 & 44 & 269 & 192 & 93 & 105 & 52 \\
\hline 93 & 225 & 146 & 207 & 49 & 251 & 200 & 91 & 143 & 54 \\
\hline 94 & 240 & 129 & 192 & 47 & & & 81 & 140 & 45 \\
\hline 95 & 237 & 129 & 208 & 51 & & & 101 & 130 & 47 \\
\hline 96 & 216 & 121 & 198 & 39 & & & 92 & 132 & 42 \\
\hline 97 & 243 & 134 & 198 & & & & 88 & 122 & 46 \\
\hline 98 & 246 & 135 & 210 & & & & 88 & 119 & 48 \\
\hline 99 & 209 & 147 & 179 & & & & 101 & 126 & 58 \\
\hline 100 & 201 & 100 & 187 & & & & 85 & 125 & 64 \\
\hline
\end{tabular}


Table 1. Continued

\begin{tabular}{|c|c|c|c|c|c|c|c|c|c|}
\hline \multirow{2}{*}{ Intensity (dB) } & \multicolumn{3}{|c|}{$\begin{array}{c}\text { Stonecutter } \\
\text { Conditions (Numbers) }\end{array}$} & \multicolumn{3}{|c|}{$\begin{array}{c}\text { Carpenter Condition } \\
\text { (Numbers) }\end{array}$} & \multicolumn{3}{|c|}{$\begin{array}{c}\text { Steelworkers } \\
\text { (Numbers) }\end{array}$} \\
\hline & $\begin{array}{l}1 \text { st } \\
\text { Day }\end{array}$ & $\begin{array}{l}\text { 2nd } \\
\text { Day }\end{array}$ & $\begin{array}{l}\text { 3rd } \\
\text { Day }\end{array}$ & $\begin{array}{l}1 s t \\
\text { Day }\end{array}$ & $\begin{array}{l}\text { 2nd } \\
\text { Day }\end{array}$ & $\begin{array}{l}\text { 3rd } \\
\text { Day }\end{array}$ & $\begin{array}{l}1 s t \\
\text { Day }\end{array}$ & $\begin{array}{l}\text { 2nd } \\
\text { Day }\end{array}$ & $\begin{array}{l}\text { 3rd } \\
\text { Day }\end{array}$ \\
\hline 101 & 227 & 140 & 203 & & & & 115 & 128 & 57 \\
\hline 102 & 242 & 125 & 185 & & & & 93 & 127 & 52 \\
\hline 103 & 222 & 131 & & & & & 79 & 123 & 43 \\
\hline 104 & 221 & 151 & & & & & 92 & 110 & 60 \\
\hline 105 & 225 & 111 & & & & & 85 & 115 & 57 \\
\hline 106 & 204 & 126 & & & & & 92 & 130 & 64 \\
\hline 107 & & 142 & & & & & 98 & 119 & 46 \\
\hline 108 & & 126 & & & & & 92 & & 52 \\
\hline 109 & & 143 & & & & & 83 & & 54 \\
\hline 110 & & & & & & & 101 & & 52 \\
\hline 111 & & & & & & & 90 & & 63 \\
\hline 112 & & & & & & & 101 & & 57 \\
\hline 113 & & & & & & & & & 57 \\
\hline 114 & & & & & & & & & 63 \\
\hline $\begin{array}{l}\text { Number of } \\
\text { recorded data }\end{array}$ & 4,927 & 3,248 & 3,524 & 562 & 2,320 & 1,721 & 2,600 & 2,827 & 1,610 \\
\hline Mean & 95.50 & 97.14 & 93.48 & 90.49 & 88.98 & 88.95 & 98.50 & 96.04 & 99.79 \\
\hline
\end{tabular}

Moreover, Figure 8 schematically depicts the impact of harmful noise on the duration of the working times of some workers who participated in the SH's testing. For example, a worker named $1-1$ in the figure, in fact, less than $1 \mathrm{~h}$, has been exposed to noise pollution higher than the standards rate but, according to the article's analysis, this person is the same as someone he has spent more than $7 \mathrm{~h}$ working. Results show the impact of noise pollution in workers' working conditions and the necessity of applying protective strategies from noise pollutions such as limiting the exposure time, using PPE, managing the source of sounds, etc. 


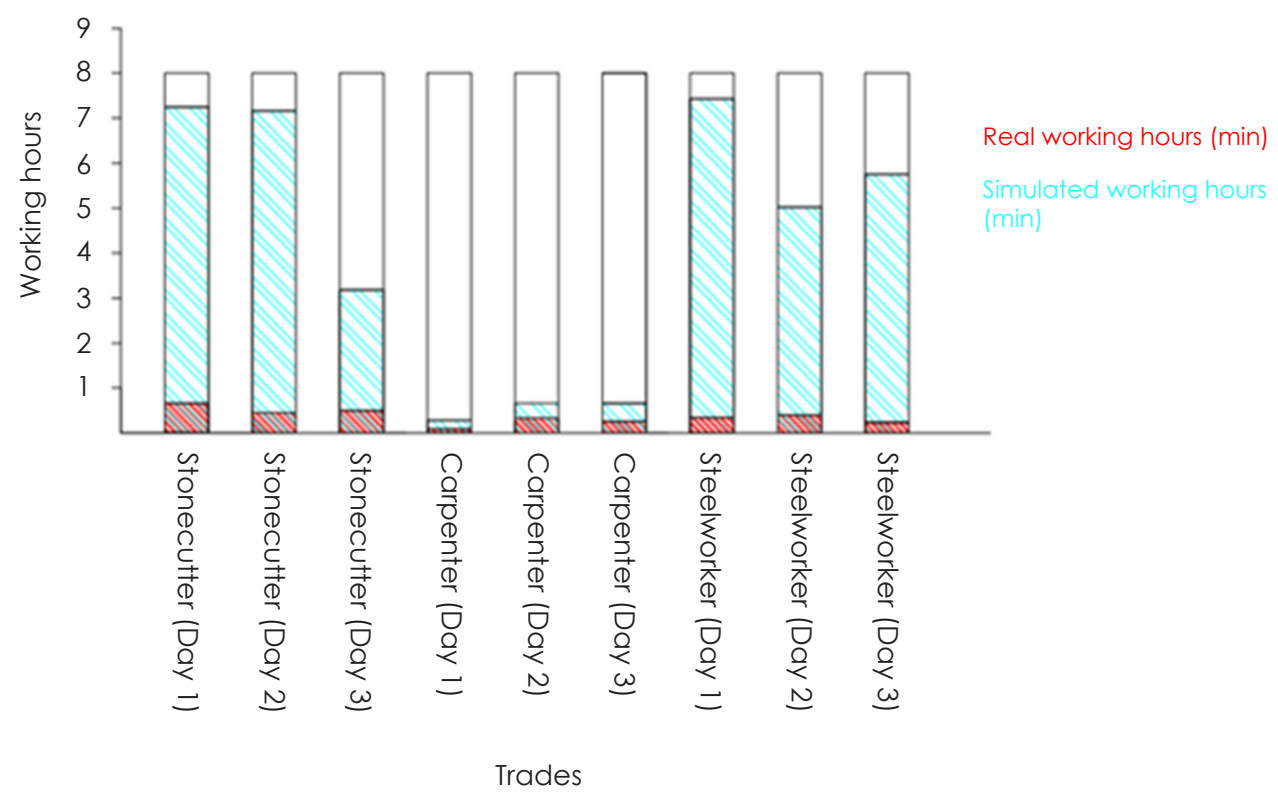

Figure 8. The impact of harmful noise on the duration of the working times

Regarding different authors' limitations, such as the lack of proper financial resources or lack of enough time, the case study was constrained to some buildings' projects and some limited careers. Still, the designed SH and the proposed approach for measuring the actual (simulated) working hours can be applied in a wide range of projects and jobs to monitor the health conditions of workers concerning the hearing ability.

\section{DISCUSSION}

Hearing problems as one of the most common diseases emerging in the construction industry is noise pollution in projects. This article's proposal solution encompasses two components: The hardware device and the control framework to increase the level of hearing health of workers in the construction industry. While developing the hardware device section, the $\mathrm{SH}$ was developed according to the concept of IOT. IOT provides the advantage of permanent and online noise pollution control for HSE project officials. Without utilising lOT technology, it is impossible to control all people simultaneously and permanently due to the wide range of activities and people in construction projects. Recoding and analysing long-term noise pollution status data can also be identified for the HSE team as a pattern of existing noise pollution in projects. These are some of the opportunities that utilising IOT provides us with. Although the IOT in an SH has created various benefits, it should be noted that it also has some limitations. One of the most important limitations is the accessibility of stable Internet connection and the proper network to transfer data. Although this is not a significant challenge in urban workshops, it is difficult to use different systems 
such as Wi-Fi in workshops outside the city because of the limited access to required infrastructures. Therefore, in these workshops, additional expenses, such as using a local Internet system with the installation of specific antennas, should be followed, which can reduce the incentives of project managers to use this system. Another major challenge in using the $\mathrm{SH}$ is the cost. Developing the device costs roughly USD50. Compared to the typical helmet cost that only costs around USD15, developing the SH is costly. The expense of implementing the SH may decrease its support for utilising in projects. To address this problem, the SH can be used for occupations that are more susceptible to hearing problems. Another notable fact to consider is that factory-based manufacturing and mass-production reduces the cost of developing $\mathrm{SH}$. Because this controlling system should be utilised for the entire workers and constructors to be sure about whole workers' health, myriad SHs are needed in workshops and construction projects. Therefore, mass-production and factory manufacturing are an aweinspiring cost-saving way for projects.

From the proposed framework's perspective, this article has also attempted to develop a method to eliminate noise pollution on people working in workshops. This method could create a work schedule for people exposed to excessive noise, as increasing the intensity of sound reduces the time allowed for each person. Although this article proposes a semi-automated template in Microsoft Excel files, future research can focus on designing a web-based system or a mobile application that automates all steps.

\section{CONCLUSION}

Since the prevalence of hearing loss in the construction industry is more substantial than in other industries, this article intends to cover this topic by presenting an innovative approach to controlling hearing loss by protecting ears from harmful sounds. To do that, there are two strategies: (1) To prevent harmful sounds from reaching ears by using PPE or getting away from the source of sounds and (2) To limit the time of exposure to harmful sounds. The main problem is that workers are not aware that they are in detrimental situations. This article applied a new loT-based technology called $\mathrm{SH}$ to solve this problem. The SH was designed to alarm workers and the HSE team in disastrous situations. Different hardware was studied and after identifying the appropriate ones, the software aspect was considered and the programming required for designing this wearable device was done. After calibration, the workers used the SH in the construction environment to determine the work's practical results. Information collected by computer systems has been processed and the results are presented. The results of this research can be summarised in two practical and theoretical categories. In the practical aspect, a new wearable device was developed to enhance individual health and safety. Developing the $\mathrm{SH}$ is one of the important results of this research. The helmet has capabilities beyond the ordinary helmet. The important aspect of designing this $\mathrm{SH}$ is communicating online and in realtime with workers and HSE teams to alarm the existence of harmful situations concerning the intensity of sounds. Moreover, the device can store the sound data to analyse the allowable duration of working time based on the existing health standard. 
In the theoretical part of the study, the international standards on hearing damage during the construction industry's activity were studied. A new approach was developed to calculate each worker's actual working time concerning exposure to the harmful sounds. Three groups including stonecutters, steelworkers and carpenters were considered and the proposed approach was applied to the collected information. The results showed that steelworkers are more exposed to sounds than other surveyed careers. Moreover, results showed that harmful sounds can be able to reduce the working time substantially.

This article has been conducted with an innovative idea and with the use of state-of-the-art technology, many ideas for future works can be created. This idea was implemented on the helmet while other wearable packages can be developed and compared with the SH model's weaknesses and strengths. Moreover, such the same model can be presented to measure the light and temperature of the worker's environment and then compare them with standards.

\section{REFERENCES}

Abbasianjahromi, H. and Talebian, R. (2018). Identifying the most important occupational diseases in the construction industry: Case study of building industry in Iran. International Journal of Construction Management, 21 (3): 235-245. https://doi.org/10.1080/15623599.2018.1518657

Couth, S., Mazlan, N., Moore, D.R., Munro, K.J. and Dawes, P. (2019). Hearing difficulties and tinnitus in construction, agricultural, music and finance industries: Contributions of demographic, health and lifestyle factors. Trends in Hearing, 23: 1-15. https://doi.org/10.1177\%2F2331216519885571.

Dave, B., Buda, A., Nurminen, A. and Främling, K. (2018). A framework for integrating BIM and loT through open standards. Automation in Construction, 95: 35-45. https://doi.org/10.1016/j.autcon.2018.07.022.

De La Hoz-Torres, M., Aguilar-Aguilera, A.J., Martínez-Aires, M. and Ruiz, D.P. (2020). Practical use of noise mapping to reduce noise exposure in the construction industry. In: Arezes, P., Baptista, J.S., Barroso, M.P., Carneiro, P., Cordeiro, P., Costa, N., Melo, R.B., Miguel, A.S. and Perestrelo, G. (eds.), Occupational and Environmental Safety and Health II. Cham, Switzerland: Springer, 209-216. https://doi.org/10.1007/978-3-030-41486-3_23.

Dement, J., Welch, L.S., Ringen, K., Cranford, K. and Quinn, P. (2018). Hearing loss among older construction workers: Updated analyses. American Journal of Industrial Medicine, 61 (4): 326-335. https://doi.org/10.1002/ajim.22827.

Ding, K., Shi, H., Hui, J., Liu, Y., Zhu, B., Zhang, F. and Cao, W. (2018). Smart steel bridge construction enabled by BIM and Internet of Things in Industry 4.0: A framework. In 2018 IEEE 15th International Conference on Networking, Sensing and Control (ICNSC). Piscataway, NJ: Institute of Electrical and Electronics Engineers (IEEE), 1-5. https://doi.org/10.1109/ICNSC.2018 .8361339 .

Fernández, M.D., Quintana, S., Chavarría, N. and Ballesteros, J.A. (2009). Noise exposure of workers of the construction sector. Applied Acoustics, 70(5): 753-760. https://doi.org/10.1016/j.apacoust.2008.07.014. 
Hong, O. (2005). Hearing loss among operating engineers in American construction industry. International Archives of Occupational and Environmental Health, 78: 565-574. https://doi.org/10.1007/s00420-005 -0623-9.

House, R.A., Sauvé, J.T. and Jiang, D. (2010). Noise-induced hearing loss in construction workers being assessed for hand-arm vibration syndrome. Canadian Journal of Public Health, 101: 226-229. https://doi.org/10.1007/ BF03404378.

Kanan, R., Elhassan, O. and Bensalem, R. (2018). An loT-based autonomous system for workers' safety in construction sites with real-time alarming, monitoring and positioning strategies. Automation in Construction, 88: 73-86. https://doi.org/10.1016/j.autcon.2017.12.033.

Kantová, R. (2017). Construction machines as a source of construction noise. Procedia Engineering, 190: 92-99. https://doi.org/10.1016/j.proeng.2017.05 .312.

Kim, S.H., Ryu, H.G. and Kang, C.S. (2018). Development of an loT-based construction site safety management system. In K.J. Kim and N. Baek (eds.), Information Science and Applications 2018: ICISA 2018. Cham, Switzerland: Springer, 617-624. https://doi.org/10.1007/978-981-13-1056-0_60.

Lee, S.C., Kim, J.H. and Hong, J.Y. (2019). Characterizing perceived aspects of adverse impact of noise on construction managers on construction sites. Building and Environment, 152: 17-27. https://doi.org/10.1016/j.buildenv.2019 .02 .005 .

Leensen, M., van Duivenbooden, J. and Dreschler, W. (2011). A retrospective analysis of noise-induced hearing loss in the Dutch construction industry. International Archives of Occupational and Environmental Health, 84: 577-590. https://doi.org/10.1007/s00420-010-0606-3.

Li, L. (2018). China's manufacturing locus in 2025: With a comparison of "Madein-China 2025" and "Industry 4.0". Technological Forecasting and Social Change, 135: 66-74. https://doi.org/10.1016/j.techfore.2017.05.028.

Louis, J. and Dunston, P.S. (2018). Integrating loT into operational workflows for real-time and automated decision-making in repetitive construction operations. Automation in Construction, 94: 317-327. https://doi.org/10 .1016/j.autcon.2018.07.005.

Marchiori, M., Demartini, P., Albano, V. and Barbini, F.M. (2017). Occupational health and safety management system effectiveness: Reflections from theory and insights from practice. International Journal of Environment Health, 8(2): 164-184. https://dx.doi.org/10.1504/IJENVH.2017.083976.

Masterson, E.A., Tak, S., Themann, C.L., Wall, D.K., Groenewold, M.R., Deddens, J.A. and Calvert, G.M. (2013). Prevalence of hearing loss in the United States by industry. American Journal of Industrial Medicine, 56(6): 670-681. https://doi.org/10.1002/ajim.22082

Ngu, A.H., Gutierrez, M., Metsis, V., Nepal, S. and Sheng, Q.Z. (2016). loT middleware: A survey on issues and enabling technologies. IEEE Internet of Things Journal, 4(1): 1-20. https://doi.org/10.1109/JIOT.2016.2615180.

Ning, X., Qi, J., Wu, C. and Wang, W. (2019). Reducing noise pollution by planning construction site layout via a multi-objective optimization model. Journal of Cleaner Production, 222: 218-230. https://doi.org/10.1016/ j.jclepro.2019.03.018. 
$\mathrm{NIOSH}$ (National Institute for Occupational Safety and Health) (2003). Engineering and technology solutions for noise control. Available at: http://www .cdc.gov/niosh/topics/noise/currentresearch/engineeringsolutions.html

Niu, Y., Anumba, C. and Lu, W. (2019). Taxonomy and deployment framework for emerging pervasive technologies in construction projects. Journal of Construction Engineering and Management, 145(5): 04019028. https://doi.org/10.1061/(ASCE)CO.1943-7862.0001653.

OSHA (Occupational Safety and Health Administration) (1998). Occupational noise exposure. Available at: https://www.osha.gov/SLTC/noisehearing conservation.

Park, H. and Rhee, S.-B. (2018). loT-based smart building environment service for occupants' thermal comfort. Journal of Sensors, 2018: 1757409. https://doi .org/10.1155/2018/1757409.

Sakhare, P. and Chakravarty, S. (2020). A study on the assessment of noise induced hearing loss among adult factory workers. International Journal of Scientific Research, 8(12): 15-17. https://www.doi.org/10.36106/ijsr.

Seixas, N.S., Neitzel, R., Stover, B., Sheppard, L., Daniell, B., Edelson, J. and Meischke, H. (2011). A multi-component intervention to promote hearing protector use among construction workers. International Journal of Audiology, 50(Supp. 1): S46-S56. https://doi.org/10.3109/14992027.2010 .525754 .

Silva, B.N., Khan, M. and Han, K. (2018). Internet of things: A comprehensive review of enabling technologies, architecture and challenges. IETE Technical Review, 35(2): 205-220. https://doi.org/10.1080/02564602.2016.1276416.

Suter, A.H. (2002). Construction noise: Exposure, effects and the potential for remediation; A review and analysis. AlHA Journal, 63(6): 768-789. https://doi.org/10.1080/154281 10208984768.

Szymański, P. (2017). Risk management in construction projects. Procedia Engineering, 208: 174-182. https://doi.org/10.1016/j.proeng.2017.11.036.

Tang, S., Shelden, D.R., Eastman, C.M., Pishdad-Bozorgi, P. and Gao, X. (2019). A review of building information modeling (BIM) and the Internet of things (loT) devices integration: Present status and future trends. Automation in Construction, 101: 127-139. https://doi.org/10.1016/j.autcon.2019.01.020.

Xu, G., Li, M., Chen, C.-H. and Wei, Y. (2018). Cloud asset-enabled integrated IoT platform for lean prefabricated construction. Automation in Construction, 93: 123-134. https://doi.org/10.1016/j.autcon.2018.05.012.

Zhou, C. and Ding, L. (2017). Safety barrier warning system for underground construction sites using Internet-of-Things technologies. Automation in Construction, 83: 372-389. https://doi.org/10.1016/j.autcon.2017.07.005. 